\title{
Bone Mineral Density and Bone Metabolism In Children Treated for Bone Sarcomas
}

\author{
ELENA RUZA, LUIS SIERRASESÚMAGA, CRISTINA AZCONA, AND ANA PATIÑO-GARCIA \\ Department of Pediatrics, University of Navarra and University Clinic, E31080 Pamplona, Spain
}

\begin{abstract}
In adolescent bone sarcoma patients, bone mass acquisition is potentially compromised at a time in which it should be at a maximum. To evaluate the problem we measured bone mineral density (BMD) and serum markers of bone formation and resorption in a series of pediatric patients with bone tumors. BMD was measured by dual-energy $\mathrm{x}$-ray absorptiometry, at clinical remission, for lumbar spine and the neck of the femur in 38 osteosarcoma and 25 Ewing's sarcoma patients. Mean age was 20.65 and 19.13 y respectively. Serum markers of bone metabolism were: OC, PICP, ICTP, $25-\mathrm{OH}$ vit $\mathrm{D}$ and $1,25-(\mathrm{OH})_{2}$ vit D, IGF-I, IGFBP-3 and intact PTH. Serum was sampled throughout anti-tumoral treatments and followup. We analyzed 85 samples from 59 osteosarcoma patients and 54 samples from 36 Ewing's sarcoma patients. Patients had decreased lumbar and femoral BMD. The decrease was more pronounced in pubertal patients compared with those who had completed pubertal development at the time of disease diagnosis. Multivariate analysis indicated that sex, age, weight and BMI were significant in lumbar BMD depletion. Weight and BMI were significant in femoral BMD depletion. Serum markers of bone formation (PICP and OC) and resorption (ICTP) were, throughout, lower than reference values. Significant alterations in other markers were also observed. Up to a third of osteosarcoma and Ewing's sarcoma patients in clinical remission had some degree of BMD deficit. The corresponding increased risk of pathologic bone fractures constitutes a reduction in future quality of life. (Pediatr Res 59: 866-871, 2006)
\end{abstract}

$\mathrm{B}$ one growth and mineralization begin during fetal development and continue, at different rates, throughout infancy and adolescence until the accrued bone mass peak in the third decade of life (1). During infancy and adolescence two processes are involved in bone mass acquisition: bone neoformation from the growth cartilage (endochondral ossification) and remodeling of previously synthesized bone (2). If an optimal peak bone mass is not attained during adolescence, the risk of osteoporosis and pathologic fractures during adulthood is increased.

There are various studies of bone growth and maintenance in child cancer patients but few large series are available (3-5). Best studied have been children treated for acute lymphoblastic leukemia (ALL) who are particularly at risk for

Received August 16, 2005; accepted January 23, 2006.

Correspondence: Ana Patiño García, Ph.D., Laboratory of Pediatrics, Los Castaños Building, University of Navarra, 31080 Pamplona, Spain; e-mail: apatigar@unav.es

Partial financial support for this research project was provided by the Department of Health of the Gobierno de Navarra and by the Fondo de Investigación Cooperativa (Health Research Fund), the Ministry of Health, and the Redes Temáticas de Investigación Cooperativa (Thematic Networks of Cooperative Research) - Cáncer C10/03.

DOI: 10.1203/01.pdr.0000219129.12960.c2 bone mineral density (BMD) deficits after cranial irradiation $(6-8)$. Some pediatric solid tumors have been included in the larger series, which tend to be rather heterogeneous, but there is scant BMD data for pediatric bone sarcomas, osteosarcomas and Ewing's sarcomas (9).

Children undergoing anti-tumoral treatments are at risk from several factors that may interfere in bone mass acquisition and maintenance. These factors include: the suboptimal nutritional status, prolonged immobilization, hormonal disorders, hypogonadism and treatments with chemotherapy, radiotherapy and with glucocorticoids. These factors have a strong impact on patients with bone tumors because such tumours are typically diagnosed during puberty when bone mass acquisition is at a maximum (10).

Although alteration of bone metabolism and mineralization is a well-known secondary effect of chemotherapy, it is difficult to determine the specific effects of each chemotherapeutic agent on bone tissue due to the use of multiple drugs in the current anti-tumoral protocols for bone sarcomas. High-dose methotrexate (HD-MTX) is characteristic of osteosarcoma treatment and it has been suggested that methorexate (and also cyclophosphamide) have a particularly strong effect on bone mineral accretion and skeletal development (11).

The aim of this longitudinal and retrospective study was to determine the scale of the alteration in bone mineral metabolism, at clinical remission and throughout the anti-tumoral treatment, for a homogeneous group of survivors of malignant bone tumors (osteosarcoma and Ewing's sarcoma).

\section{PATIENTS AND METHODS}

All the patients included in this study were treated and followed up at the Oncology Unit of the Department of Pediatrics of the University Clinic in Pamplona, Spain. Ethical approval was granted by the Ethics Committee of the University Clinic and in all cases informed consent was obtained from the patient or from parents.

Patients who had other diseases (additional to the bone tumor) which might affect bone metabolism, and patients for whom there was incomplete information about the treatment protocol (type and dose of cytostatic drugs), evolution and/or complications were excluded from this study.

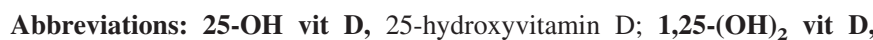
1,25-di hydroxyvitamin D; ALL, acute lymphoblastic leukaemia; BMD, bone mineral density; BMI, body mass index; DXA, dual energy X-ray absorptiometry; ICTP, cross-linked telopeptide of type 1 collagen; OC, osteocalcin; PICP, procollagen type I C-terminal peptide; PTH, parathormone; SDS, standard deviation score 
The location of primary tumors, according to whether or not they affected weight-bearing bones, is given in Table 1. Information, extracted from medical records, about the occurrence of fractures and/or other orthopedic complications was included in the analysis.

BMD quantification by dual energy X-ray absorptiometry. BMD was measured at clinical remission for 38 patients with osteosarcoma (20 female, 18 male) and for 25 with Ewing's sarcoma (11 female, 14 male). Mean age at BMD measurement was 20.65 y (SD, 4.42) for osteosarcoma patients and 19.13 (SD, 4.20) for Ewing's sarcoma patients. Mean duration of remission was 6.12 y (SD, 3.67) (over 5 y in $52.6 \%$ of cases) in patients with osteosarcomas, and 6.11 y (SD, 3.73) (over 5 y in $57.7 \%$ of cases) in patients with Ewing's sarcomas.

Areal bone mineral densities (areal-BMD, $\mathrm{g} / \mathrm{cm}^{2}$ ) at the lumbar spine (L2-L4) and the neck of the right femur (left femur if the primary location was the right femur) were measured by dual energy x-ray absorptiometry (DXA; Hologic QDR 4500W v9.8 Elite, Woltham, MA). The short-term reproducibility expressed as the coefficient of variation for both determinations was $0.8 \%$ to $1 \%$. To make our data (expressed in $\mathrm{g} / \mathrm{cm}^{2}$ ) comparable to those of the Spanish reference population, which have been determined by LunarDXA $(12,13)$, we applied the formula described by Genant et al. (14). Thus transformed, our data were compared with that of the reference population and the results expressed as Z-scores.

Anthropometric data. Standing height was measured with a Harpender stadiometer (Holtain Ltd., Crymych, UK) and always by a trained operator. Body weight was measured with a digital scale (Seca, Hanover, MD) with a sensitivity of $100 \mathrm{~g}$. Patients were weighed barefoot and after overnight fasting. The anthropometric data were obtained at the time of BMD determination. Height, weight and body mass index (BMI, $\mathrm{kg} / \mathrm{m}^{2}$ ) were compared with those of the Spanish reference population (15) and expressed as SD scores (SDS).

Analytical methods: Biochemical and hormonal markers of bone metabolism. We analyzed 85 serum samples from 59 osteosarcoma patients and 54 serum samples from 36 Ewing's sarcoma patients. Patients with altered hepatic and/or renal function and endocrinologic disorders were excluded. Thus, we excluded 12 osteosarcoma and four Ewing's sarcoma patients due to hepatic disease (11 osteosarcomas and three Ewing's sarcomas due to a transitory increase of transaminases, one osteosarcoma with chronic hepatic insufficiency and one Ewing's sarcoma with cholelithiasis). We excluded 15 osteosarcomas and three Ewing's sarcomas due to renal diseases (one osteosarcoma and two Ewing's sarcomas due to hemorrhagic cystitis, three osteosarcomas and one Ewing's sarcoma due to acute renal insufficiency, one osteosarcoma due to nephrolithiasis and five osteosarcomas due to tubulointerstitial nephropathy with chronic renal insufficiency). The above patients were excluded because, given the elimination pathways of the biochemical markers of bone formation and resorption, these renal and hepatic diseases could reasonably be expected to increase the serum levels of the markers.

Samples were classified according to whether they had been extracted at diagnosis, at end of treatment, at remission or during tumoral progression (defined as the occurrence of disease at a distance from the primary tumor which required an additional anti-tumoral treatment to the standard protocol) (Table 2). In all cases, plasma was obtained at $08: 00 \mathrm{~h}$ whenever possible and stored at $-80^{\circ} \mathrm{C}$ until use.

To evaluate bone formation, intact osteocalcin (OC) (BioSource Europe, Nivelles, Belgium), procollagen type I C-terminal peptide (PICP) (Orion Diagnostica, Espoo, Finland) were measured by immunoradiometric assay (IRMA) and RIA (RIA) respectively. The sensitivity of the OC assay was 0.15 $\mathrm{ng} / \mathrm{mL}$ and of the PICP assay was $1.2 \mu \mathrm{g} / \mathrm{L}$; the intra- and interassay coefficients of variation (CV) were $2.9-4.7 \%$ and $5.3-6.3 \%$ for OC, and $3.1-3.2 \%$ and $4.0-5.8 \%$ for PICP, respectively. To evaluate bone resorption, cross-linked telopeptide of type 1 collagen (ICTP) (Orion Diagnostica, Espoo, Finland) was measured by RIA; the assay sensitivity was $0.5 \mu \mathrm{g} / \mathrm{L}$; the intraand interassay CV was $2.8-6.2 \%$ and $4.1-7.9 \%$, respectively. To evaluate the

Table 1. Classification of primary tumors according to their location in weight-bearing bones

\begin{tabular}{lcc}
\hline Type of bone & $\begin{array}{c}\text { Osteosarcoma } \\
(\%)\end{array}$ & $\begin{array}{c}\text { Ewing's sarcoma } \\
(\%)\end{array}$ \\
\hline Weight-bearing bones & & \\
Tibia & 46 & 28 \\
Femur & 37 & 16 \\
Pelvis & 0 & 8 \\
Non-weight-bearing bones* & 17 & 48 \\
\hline
\end{tabular}

* Non-weight-bearing bones: humerus, fibula, radius, cranial, rib, foot and clavicle.
Table 2. Distribution, by sampling schedule, of the samples obtained for analysis of biochemical and hormonal markers of bone metabolism

\begin{tabular}{lccc}
\hline & Osteosarcoma & Ewing's sarcoma & Total \\
\hline At diagnosis & 8 & 6 & 14 \\
End of treatment & 10 & 6 & 16 \\
Clinical remission & 54 & 32 & 86 \\
Tumoral progression & 13 & 10 & 23 \\
\hline
\end{tabular}

growth hormone axis, serum IGF I (IGF-I) and IGF binding protein 3 (IGFBP-3) (Diagnostic Systems Laboratories Inc., Webster, TX, U.S.A.) were analyzed by IRMA; the assay sensitivity was 0.8 and $0.5 \mathrm{ng} / \mathrm{mL}$; the intra- and interassay $\mathrm{CV}$ were $3.0 \%$ and $4.3 \%$ for IGF-I and $3.0 \%$ and $2.1 \%$ for IGFBP-3, respectively. To evaluate vitamin D metabolism, serum concentrations of 25-hydroxyvitamin D (25-OH vit D) and 1,25-di hydroxyvitamin D $\left(1,25-(\mathrm{OH})_{2}\right.$ vit D) (BioSource Europe, Nivelles, Belgium) were measured by RIA; the assay sensitivity was $0.6 \mathrm{ng} / \mathrm{mL}$ and $1.0 \mathrm{pg} / \mathrm{mL}$; the intra- and interassay $\mathrm{CV}$ were $6.1-7.9 \%$ and $7.1-8.2 \%$ for $25-\mathrm{OH}$ vit $\mathrm{D}$ and $7.8-12.4 \%$ and $10-12.1 \%$ for $1,25-(\mathrm{OH})_{2}$ vit $\mathrm{D}$, respectively. Intact parathormone was measured by chemiluminescent enzyme immunometric assay (PTH, Diagnostic Products Corporation, Los Angeles, CA); the assay sensitivity was 1 $\mathrm{pg} / \mathrm{mL}$; the intra- and interassay CV was $5.4-7.0 \%$ and $5.0-5.5 \%$, respectively. Standard methods were used for thyroid-stimulating hormone (TSH) evaluation (Abbott Laboratories, Illinois) to exclude hyper and hypothyroidism; follicle stimulating hormone (FSH), LH ( $\mathrm{LH}$ ) (Abbott Laboratories, Illinois), testosterone in males and estradiol in females to exclude hypogonadism (Diagnostic Products Corporation, Los Angeles, CA).

Statistical analysis. Statistical analyses were carried out with SPSS v11.0 (Statistical Package for the Social Sciences, Chicago) and values of $p<0.05$ were considered significant.

We used the Student $t$-test to compare the SDS or Z-scores obtained from patient data and Spanish reference population data.

The variation of anthropometric values and BMD according to age, sex, type of tumor and remission duration was evaluated with the Student $t$-test for independent samples or by the Mann-Whitney U-test.

The correlation between BMD of patients in clinical remission and the clinical factors potentially involved in BMD was evaluated by multiple linear regression (Table 3).

The relationship between serum markers of bone resorption/formation and BMD (DXA values) was determined by Spearman's correlation.

Table 3. Description of the clinical factors included in the analysis of the BMD in pediatric patients with bone tumors at clinical remission

\begin{tabular}{|c|c|c|}
\hline & Osteosarcoma & Ewing's sarcoma \\
\hline Age at diagnosis (years) & $13.79(11.58 ; 15.08)^{*}$ & $12.06(3.78) \dagger$ \\
\hline Age at DXA(years) & $20.65(4.42)$ & $19.13(4.20)$ \\
\hline Height $(\mathrm{cm})$ & $169.49(10.01)$ & $169(161.20 ; 176.0)$ \\
\hline Height (SDS) & $0.54(1.33) \ddagger$ & $0.14(1.12)$ \\
\hline Weight (Kg) & $60.83(11.10)$ & $61.37(15.94)$ \\
\hline Weight (SDS) & $0.30(-0.55 ; 0.85)$ & $-0.20(-0.50 ; 0.85)$ \\
\hline $\operatorname{BMI}\left(\mathrm{Kg} / \mathrm{m}^{2}\right)$ & $20.67(19.25 ; 22.88)$ & $21.16(18.24 ; 22.98)$ \\
\hline BMI (SDS) & $0(-0.75 ; 0.55)$ & $0.10(-0.80 ; 0.75)$ \\
\hline Treatment duration (months) & $12(11 ; 15)$ & $11(10.5 ; 15.5)$ \\
\hline Hospitalization (months) & $6.46(4.96 ; 9.11)$ & $4.96(3.36 ; 7.25)$ \\
\hline Remission time (years) & $5.92(3.14 ; 9.26)$ & $5(3.0 ; 8.21)$ \\
\hline \multicolumn{3}{|l|}{ Cytostatic drugs } \\
\hline Methotrexate $\left(\mathrm{g} / \mathrm{m}^{2}\right)$ & $62.77(41.15 ; 90.10)$ & $0.23(0.21 ; 0.28)$ \\
\hline Cyclophosphamide $\left(\mathrm{g} / \mathrm{m}^{2}\right)$ & $4.47(2.20)$ & $17.71(14.66 ; 21.78)$ \\
\hline Bleomycin $\left(\mathrm{mg} / \mathrm{m}^{2}\right)$ & $100.10(45.60)$ & $173.95(56.94)$ \\
\hline Cisplatin $\left(\mathrm{mg} / \mathrm{m}^{2}\right)$ & $477.60(131.70)$ & - \\
\hline Adriamycin $\left(\mathrm{mg} / \mathrm{m}^{2}\right)$ & $424.21(114.37)$ & $432.08(134.03)$ \\
\hline Actinomycin & 4.96( & $9.20(2.91)$ \\
\hline Vincristine $\left(\mathrm{mg} / \mathrm{m}^{2}\right)$ & $6.43(3.12 ; 8.49)$ & $21.49(17.79 ; 32.18)$ \\
\hline
\end{tabular}


The relationship between PICP and ICTP and the remission time until determination was established by the median test and the Mann-Whitney U-test for the five-year cut-off. The scoring of biochemical and hormonal markers according to the reference ranges provided by the manufacturers was determined by the nonparametric binomial test.

\section{RESULTS}

Bone mineral density determination by DXA. The lumbar and femoral BMD of our pediatric bone cancer patients was significantly lower than that of the sex and age-paired reference population (Table 4). Male osteosarcoma patients had lower BMD than female patients $(p=0.04)$. We found no significant difference in BMD, whether lumbar or femoral, of patients with osteosarcoma compared with that of patients with Ewing's sarcoma. Neither did we find any association between BMD and the time lag from the end of treatment until the moment of BMD measurement.

On the basis of lumbar and femoral BMD respectively, $33.9 \%$ and $25.4 \%$ of patients had BMD in the range between -1 and -2 SDS. Similarly, $9.7 \%$ and $17.5 \%$ of patients had BMD of less than -2 SDS (Fig. 1). The incidence of fractures was also studied but no significant differences were detected between groups. In addition to the 17 patients with pathologic fractures, as a consequence of the tumor and/or the antitumoral treatments 18 patients presented infections of the peri-tumoral soft tissues, seven chronic osteomyelitis, and a further three had to have a limb amputated.

BMD was related to age at diagnosis and treatment onset. Lumbar BMD in pubertal patients was significantly lower than that of the reference population $(p<0.001)$ and, furthermore, tended to be lower than that of patients who had completed pubertal development at the time of diagnosis $(p=0.08)$. The difference from the reference population was even more pronounced for femoral BMD in osteosarcomas and Ewing's sarcomas ( $p<0.001$ and $p=0.003$ respectively).

We used multiple linear regression to analyze the relationship between BMD of patients in clinical remission and the clinical factors potentially involved in BMD.

Multivariate analysis indicated that the following factors had statistically significant effects on lumbar BMD: $\operatorname{sex}(p=$ 0.002 and $p=0.012$ for areal-BMD and BMD-SDS respec- tively, BMD being higher in women than in men), age at diagnosis $(p=0.035$ for areal-BMD with BMD increasing with older age) and age DXA ( $p<0.001$ for BMD-SDS with BMD increasing with older age). Concerning the anthropometric data, only weight ( $p=0.016$ for areal-BMD) and BMI $(p=0.038$ for BMD-SDS) had a significant positive effect on BMD. Months in clinical remission showed positive correlation in the univariate analysis of areal-BMD $(p=0.017)$. Height did not influence BMD in our series, although height was statistically higher than that of the reference population.

With regard to femoral BMD, the following factors had significant effects on BMD: both weight $(p=0.001$, for areal-BMD) and BMI ( $p=0.001$, for BMD-SDS) showed a positive effect on BMD, and vincristine dose showed a weak negative effect on areal-BMD $(p=0.037)$. Surprisingly, the HD-MTX received by the osteosarcoma patients did not statistically affect the lumbar BMD. The total duration of hospitalization showed a weak negative correlation with femoral areal-BMD ( $p=0.065)$.

Analysis of the biochemical and hormonal markers of bone metabolism. At diagnosis, at the end of the anti-tumoral treatment, at clinical remission and at tumor progression, the serum levels of biochemical markers of bone formation (PICP y OC) and resorption (ICTP) were significantly lower than reference values $(p<0.001)$ (Table 5). Three patients $(18.7 \%)$ had increased levels of ICTP at the end of treatment and six (26.1\%) had increased levels at tumor progression.

The number of patients with normal ICTP levels increased linearly with time after completion of the anti-tumoral treatment $(p<0.001)$ up to a maximum at five years in clinical remission.

In comparison to reference values, patient levels of IGF-I and PTH were lower both at the time of diagnosis ( $p=0.005$ and $p=0.02$ respectively) as well as at clinical remission ( $p$ $<0.001)$. Similarly, patients at remission had lower levels of $1,25-(\mathrm{OH})_{2} \mathrm{D}(p<0.001)$. Concerning patients in disease progression, a significant number had low levels of PTH (33.3\%), $1,25-(\mathrm{OH})_{2} \mathrm{D}(15.8 \%)$ and $25-\mathrm{OH}$ vit $\mathrm{D}(26.3 \%)$; while three $(14.3 \%)$ and six (50\%) of those patients showed increased ICTP and IGF-I respectively.

Table 4. Comparative analysis of the lumbar and femoral BMD in bone sarcoma patients compared to the Spanish reference population $(12,15)$

Lumbar BMD

\begin{tabular}{|c|c|c|c|c|c|c|c|c|c|}
\hline & \multirow[b]{2}{*}{$\mathrm{n}$} & & \\
\hline & & $\begin{array}{c}\text { BMD } \\
\text { Hologic } \\
\left(\mathrm{g} / \mathrm{cm}^{2}\right)^{*}\end{array}$ & $\begin{array}{c}\text { BMD } \\
\text { Lunar } \\
\left(\mathrm{g} / \mathrm{cm}^{2}\right) \dagger\end{array}$ & $\begin{array}{c}\text { BMD } \\
\text { Lunar } \\
\text { (Z-score }) \ddagger\end{array}$ & $p$-value $\$$ & $\begin{array}{c}\text { BMD } \\
\text { Hologic } \\
\left(\mathrm{g} / \mathrm{cm}^{2}\right)\end{array}$ & $\begin{array}{c}\text { BMD } \\
\text { Lunar } \\
\left(\mathrm{g} / \mathrm{cm}^{2}\right)\end{array}$ & $\begin{array}{c}\text { BMD } \\
\text { Lunar } \\
\text { (Z-score) }\end{array}$ & $p$-value \\
\hline Osteosarcoma & 38 & $0.96(0.13)$ & $1.08(0.14)$ & $-0.76(0.96)$ & $p<0.001$ & $0.85(0.14)$ & $0.85(0.15)$ & $-0.88(1.10)$ & $p<0.001$ \\
\hline Females & 20 & $0.99(0.10)$ & $1.11(0.11)$ & $-0.46(0.82)$ & $p=0.020$ & $0.84(0.14)$ & $0.84(0.14)$ & $-0.85(1.20)$ & $p=0.005$ \\
\hline Males & 18 & $0.92(0.16)$ & $1.05(0.16)$ & $-1.11(1.02)$ & $p<0.001$ & $0.86(0.15)$ & $0.87(0.15)$ & $-0.91(1.01)$ & $p=0.001$ \\
\hline $\begin{array}{l}\text { Ewing's } \\
\text { sarcoma }\end{array}$ & 25 & $0.93(0.16)$ & $1.06(0.17)$ & $-0.84(1.05)$ & $p=0.001$ & $0.88(0.15)$ & $0.88(0.15)$ & $-0.76(1.15)$ & $p=0.003$ \\
\hline Females & 11 & $0.97(0.12)$ & $1.09(0.14)$ & $-0.74(1.20)$ & $p=0.068$ & $0.83(0.14)$ & $0.84(0.14)$ & $-0.90(1.14)$ & $p=0.025$ \\
\hline Males & 14 & $0.90(0.19)$ & $1.03(0.20)$ & $-0.92(0.95)$ & $p=0.003$ & $0.92(0.16)$ & $0.92(0.15)$ & $-0.64(1.18)$ & $p=0.063$ \\
\hline
\end{tabular}

* BMD measured by the Hologic system and expressed as mean (standard deviation).

$\uparrow$ BMD measured by the Lunar system and expressed as mean (standard deviation).

$\ddagger$ BMD measured by the Lunar system, compared to the Spanish reference population and expressed as Z-score.

$\S$ Student $t$-test for one sample. 


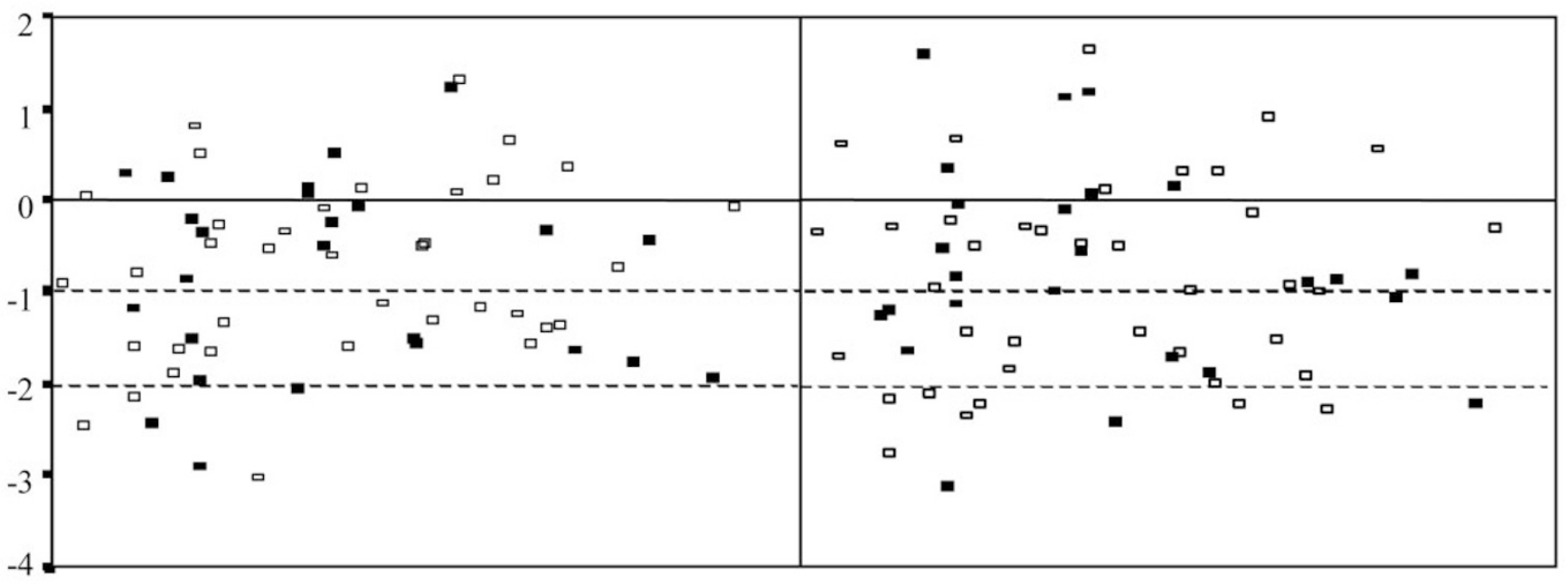

Figure 1. Representation of bone mineral density (BMD) in pediatric bone sarcoma patients at clinical remission. $\square$ osteosarcoma; $\square$ Ewing's sarcoma. Lumbar spine: 21 patients had a BMD in the range between -1 and -2 SDS and 6 of less than -2 SDS; femoral neck: 16 patients had a BMD in the range between -1 and -2 SDS and 11 of less than -2 SDS

With regard to gonadotrophins and sex hormones, four patients $(4.4 \%)$ had increased FSH and LH levels, two of them immediately after pelvic radiotherapy and two at disease progression. Two other patients had low levels of gonadotrophins after cranial radiotherapy.

The markers of bone formation (PICP and OC) and resorption (ICTP) were negatively correlated to lumbar and femoral BMD (data not shown).

\section{DISCUSSION}

Malignant bone tumors are the third most common tumor type among adolescents and young adults, with a peak incidence at about $15 \mathrm{y}$ of age. Frequently, the diagnosis of these tumors occurs during the period of maximal growth rate and bone accrual, the pubertal growth spurt. A question that we wished to address was: what are the secondary effects of undergoing a tumoral process and its treatment during this specific period of life?

The first studies of bone mass in pediatric oncology involved children with ALL (6-8,16-18). Most researchers concluded that there was a depletion of bone mass which could be detected at the time of diagnosis and that persisted in adult survivors. In some studies, patients with ALL were compared with a heterogeneous mix of patients with "other malignant tumors" which included lymphomas, CNS (CNS) tumors and sarcomas $(3,4,19-21)$. The usefulness of such comparisons is somewhat limited by the very different clinical and etiopathogenic natures of the tumors concerned.

While the low bone mass of all patients can be attributed to their low stature, both osteosarcoma and Ewing's sarcoma survivors are significantly taller than the reference population (22). This raises the question of whether the reduced BMD of a bone tumor survivor is a consequence of the anti-tumoral treatment or of the tumor itself.

Several authors have observed that weight is associated with BMD and bone mineral content both in healthy children (23-25) and cancer survivors $(3,26)$. However, Mølgaard and collaborators (27) demonstrated that bone surface area corrected by height (to give an estimate of bone width) increased with weight and that therefore the effect of weight on bone mineral content was indirect.

Typically, bone tumors are diagnosed at an older age than leukemias and other tumor types. For this reason the average age of our patients at clinical remission and, therefore, at BMD determination was approximately $20 \mathrm{y}$. Bone tumors typically occur during pubertal development. The influence of the pubertal period on bone mass has been demonstrated by many authors $(12,23,28,29)$. Some publications indicate that, independent of the age at tumor diagnosis, low BMD at an age when it should be maximal is a high risk factor for osteoporosis (4).

Table 5. Absolute values of the biochemical and hormonal markers of bone metabolism in pediatric patients with bone tumors

\begin{tabular}{lcccc}
\hline \multicolumn{1}{c}{ Marker } & Diagnosis & End of treatment & Clinical remission & Tumor progression \\
\hline PICP $(\mu \mathrm{gg} / \mathrm{L})$ & $49.30(30.16 ; 73.95)$ & $74.05(50.10 ; 104.53)$ & $49.29(39.02 ; 63.42)$ & $58.77(42.57 ; 94.19)$ \\
ICTP $(\mu \mathrm{g} / \mathrm{L})$ & $5.15(3.04 ; 6.92)$ & $6.43(4.68 ; 11.62)$ & $2.90(1.96 ; 4.58)$ & $6.09(4.48 ; 10.53)$ \\
OC $(\mathrm{ng} / \mathrm{mL})$ & $3.89(2.61 ; 5.99)$ & $3.51(2.07 ; 6.96)$ & $4.17(2.56 ; 8.18)$ & $3.81(1.98 ; 7.75)$ \\
PTH $(\mathrm{pg} / \mathrm{mL})$ & $17.40(10.47 ; 20.22)$ & - & $11.90(9.00 ; 16.30)$ & $12.40(10.70 ; 20.70)$ \\
IGF-I $(\mathrm{ng} / \mathrm{mL})$ & $109.5(67.5 ; 159)$ & - & $98.10(68.97 ; 150.25)$ & $89.40(51.65 ; 139.5)$ \\
IGFIBP3 $(\mathrm{ng} / \mathrm{mL})$ & $1335.5(1077 ; 1688)$ & - & $1331.5(1068 ; 1621)$ & $1293(875 ; 1405)$ \\
$1,25-(\mathrm{OH})_{2}$ vit D $(\mathrm{pg} / \mathrm{mL})$ & - & - & $26.05(21.00 ; 31.07)$ & $32.14(19.03 ; 44.27)$ \\
25-OH vit D $(\mathrm{ng} / \mathrm{mL})$ & - & - & $19.83(14.07 ; 23.31)$ & $13.29(9.21 ; 17.94)$ \\
\hline
\end{tabular}

Values are expressed as median (inter-quartilic range). 
Contrary to other publications (19-21,30), in our series, age at diagnosis and at DXA were determining factors for lumbar BMD, which was more severely affected in those patients who were pubertal at the time of diagnosis than in those who had already completed pubertal development.

Holzer et al. analyzed the BMD of long term $(>10 \mathrm{y})$ osteosarcoma survivors and detected that $43.7 \%$ had BMD values in the range of osteopenia and $20.8 \%$ in the range of osteoporosis (9). Similarly, the patients reported here showed significantly decreased BMD values, with an even higher incidence of osteopenia (59.7\%) and osteoporosis (27\%). However, whilst Holzer et al. used T-scores (comparison with the maximum young adult BMD) we transformed our data in Z-scores (comparison against age and gender-matched controls). Furthermore, the mean age at diagnosis was lower in the patients reported here. Despite the above differences, it can be concluded from both studies that a high number of bone sarcoma survivors show some degree of BMD deficit at an age at which BMD should be at its peak. Considering that a deficit of BMD of one SD increases the risk of pathologic fractures 2.5 -fold, such a deficit has important repercussions on future quality of life.

As mentioned above, an effect of anti-tumoral treatment on pubertal development and on bone mass acquisition has been frequently reported. The pubertal development of our patients at the time of diagnosis was concordant with their age and, although many of the young women developed amenorrhea during treatment, we did not detect any hormonal alterations at remission. There were no significant differences between the men and women in terms of BMD or biochemical markers.

Osteopathy due to methotrexate is a well known secondary effect (31); however, in our study, neither methotrexate, cyclophosfamide nor cisplatin affected BMD. We detected a slight effect of vincristine on femoral BMD only. Our results should be interpreted with a degree of caution due to the limited number of patients involved although the results do corroborate similar reports by other authors $(3,6,19-21)$ of a lack of effect of chemotherapy agents on BMD.

Another important factor with an influence on BMD in survivors of malignant tumors is the degree of immobilization and physical inactivity during treatment. Apart from orthopedic considerations, bone tumors are most often located in the lower limbs and this tends to complicate physical exercise. As an estimate of immobilization we used the total duration of hospitalization and observed that this tended to be negatively associated with BMD. This same finding has been detected for different tumors by other authors (20) who suggested that, being one of the main bones supporting body weight, the femur might be specifically affected by immobilization. The important effect on of bone in young persons shortly after chemotherapy would support a hypothesis that femur osteoporosis is induced by immobilization and that the more metabolically active lumbar spine is affected by chemotherapy, corticoids and/or hormonal disorders.

In patients who showed an asymmetric load due to an effect of the tumor and/or treatment on weight-bearing structures, one might not be surprised to find a compensatory bone deposit on the non-affected, load-bearing femur due to over- stimulation. Nevertheless, the measurement of BMD in the normal femoral neck showed a statistically significant decrease compared with the reference population of paired sex and age.

With regard to the question of whether the adverse effects of anti-tumoral treatment on bone metabolism and mineralization are reversible or not, the published data $(3,6,31,32)$ is controversial and inconsistent. In our series, we detected a weak positive correlation between remission time and lumbar BMD but the catch-up is not complete and contributes to the high risk of developing osteoporosis in the future decades of life.

Longitudinal analysis of hormonal and biochemical markers of bone metabolism has several advantages over quantification of bone mass; it gives information on the global metabolic status, can detect subtle alterations over short periods of time, is independent of the observer and gives information on the mechanisms involved in any associated clinical alteration.

In our series, the levels of markers of bone metabolism were typically below normal at diagnosis and then gradually normalized over the duration of the treatment and patient evolution. This process was particularly noticeable for ICTP, a marker of bone resorption. Nevertheless, values remained below normal ranges, which could account for the low BMD detected by DXA at remission. Growth hormone deficiency and persistent alterations in levels of vitamin D and calcium were also detected in some patients, which could be an indirect indicator of a sub-optimal normalization of bone metabolism and could suggest a higher osteoporosis risk in adulthood.

Compared with ALL patients, osteosarcoma and Ewing's sarcoma patients are diagnosed and treated at an older age which coincides with the period of maximal bone mass accrual. The timing of the tumor and treatment at such a critical period of life implies an interference that can influence the future quality of life of patients.

Some of the main limitations in the interpretation and comparison of the results of bone mass studies in survivors of pediatric bone sarcomas are the small number of patients, the heterogeneity of treatments, the occurrence of clinical complications, the different databases for calculation of BMD Z-scores and the different methods for determining BMD (areal versus volumetric BMD).

Despite the above limitations, we can report a reduction in BMD in osteosarcoma and Ewing's sarcoma patients in clinical remission and conclude that these patients suffer alterations in bone metabolism with the potential to reduce future quality of life.

Acknowledgments. We are indebted to Dr. Ignacio Monreal for helping us with the biochemical determinations. We are grateful to David Bourdon for his reading of the manuscript.

\section{REFERENCES}

1. Abrams SA 2003 Normal acquisition and loss of bone mass. Horm Res 60:71-76

2. Parfitt AM 1994 The two faces of growth: benefits and risks to bone integrity. Osteoporos Int 4:382-398

3. Henderson RC, Madsen CD, Davis C, Gold SH 1998 Longitudinal evaluation of bone mineral density in children receiving chemotherapy. J Pediatr Hematol Oncol $20: 322-326$ 
4. Aisenberg J, Hsieh K, Kalaitzoglou G, Whittam E, Heller G, Schneider R, Sklar C 1998 Bone mineral density in young adult survivors of childhood cancer. J Pediatr Hematol Oncol 20:241-245

5. Arikoski P, Voutilainen R, Kroger H 2003 Bone mineral density in long-term survivors of childhood cancer. J Pediatr Endocrinol Metab 16:343-353

6. Kadan-Lottick N, Marshall JA, Barón AE, Krebs NF, Hambidge KM, Albano E 2001 Normal bone mineral density after treatment for childhood acute lymphoblastic leukaemia diagnosed between 1991 and 1998. J Pediatr 138:898-904

7. Warner JT, Evans WD, Webb DK, Bell W, Gregory JW 1999 Relative osteopenia after treatment for acute lymphoblastic leukaemia. Pediatr Res 45:544-551

8. Atkinson SA, Halton JM, Bradley C, Wu B, Barr RD 1998 Bone and mineral abnormalities in childhood acute lymphoblastic leukaemia: influence of disease, drugs and nutrition. Int J Cancer Suppl 11:35-39

9. Holzer G, Krepler P, Koschat MA, Grampp S, Dominkus M, Kotz R 2003 Bone mineral density in long-term survivors of highly malignant osteosarcoma. J Bone Joint Surg Br 85:231-237

10. Pfeilschifter J, Diel IJ 2000 Osteoporosis due to cancer treatment: pathogenesis and management. J Clin Oncol 18:1570-1593

11. Kaste SC 2004 Bone-mineral density deficits from childhood cancer and its therapy. A review of at-risk patient cohorts and available imaging methods. Pediatr Radiol 34:373-378

12. del Río L, Carrascosa A, Pons F, Gusinyé M, Yeste D, Domenech FM 1994 Bone mineral density of the lumbar spine in white Mediterranean Spanish children and adolescents: changes related to age, sex and puberty. Pediatr Res 35:362-366

13. Yeste D, Del Río L, Carrascosa A 2000 Valores de contenido mineral óseo (CMO), densidad mineral ósea (DMO) y densidad ósea volumétrica (DMOv) en niños y adolescentes en la columna lumbar y en el fémur. En: Argente J, Carrascosa A, Gracia R, Rodríguez F (eds) Tratado de Endocrinología Pediátrica y de la Adolescencia, 2nd ed., Doyma, Barcelona, pp1501-1513.

14. Genant HK, Grampp S, Glüer CC, Faulkner KG, Jergas M, Engelke K, Hagiwara S, Van Kuijk C 1994 Universal standardization for dual x-ray absorptiometry: patient and phantom cross-calibration results. J Bone Miner Res 9:1503-1514

15. Hernandez M, Castellet J, Narvaiza JL, Rincon JM, Ruiz I, Sanchez E, Sobradillo B, Zurimendi A 1988 Curvas y tablas de crecimiento. Instituto de Investigación sobre crecimiento y Desarrollo. Fundación F Orbegozo. Editorial Garsi, Madrid

16. Atkinson SA, Fraher L, Gundberg CM, Andrew M, Pai M, Barr RD 1989 Mineral homeostasis and bone mass in children treated for acute lymphoblastic leukemia. J Pediatr 114:793-800

17. Ragab AH, Frech RS, Vietti TJ 1970 Osteoporotic fractures secondary to methotrexate therapy of acute leukemia in remission. Cancer 25:580-585

18. Halton JM, Atkinson SA, Fraher L, Webber CE, Cockshott WP, Tam C, Barr RD 1995 Mineral homeostasis and bone mass at diagnosis in children with acute lymphoblastic leukemia. J Pediatr 126:557-564

19. Arikoski P, Komulainen J, Voutilainen R, Riikonen P, Parviainen M, Tapanainen P, Knip M, Kroger H 1998 Reduced bone mineral density in long-term survivors of childhood acute lymphoblastic leukemia. J Pediatr Hematol Oncol 20:234-240
20. Arikoski P, Komulainen J, Riikonen P, Jurvelin JS, Voutilainen R, Kröger H 1999 Reduced bone density at completion of chemotherapy for a malignancy. Arch Dis Child 80:143-148

21. Arikoski P, Komulainen J, Riikonen P, Voutilainen R, Knip M, Kröger H 1999 Alterations in bone turnover and impaired development of bone mineral density in newly diagnosed children with cancer: a 1-year prospective study. J Clin Endocrinol Metab 84:3174-3181

22. Ruza E, Sotillo E, Sierrasesumaga L, Azcona C, Patino-Garcia A 2003 Analysis of polymorphisms of the vitamin D receptor, estrogen receptor, and collagen Ialpha1 genes and their relationship with height in children with bone cancer. J Pediatr Hematol Oncol 25:780-786

23. Boot AM, de Ridder MA, Pols HA, Krenning EP, de Muinck Keizer-Schrama SM 1997 Bone mineral density in children and adolescents: relation to puberty, calcium intake and physical activity. J Clin Endocrinol Metab 82:57-62

24. Glastre C, Braillon P, David L, Cochat P, Meunier PJ, Delmas PD 1990 Measurement of bone mineral content of the lumbar spine by dual-energy X-ray absorptiometry in normal children: correlations with growth parameters. J Clin Endocrinol Metab 70:1330-1333

25. Lloyd T, Rollings N, Andon MB, Demers LM, Eggli DF, Kieselhorst K, Kulin H, Landis JR, Martel JK, Orr G 1992 Determinants of bone density in young women. I.Relationships among pubertal development, total body bone mass, and total body bone density in premenarchal females. J Clin Endocrinol Metab 75:383-387

26. Vassilopoulou-Sellin R, Brosnan P, Delpassand A, Zietz H, Klein MJ, Jaffe N 1999 Osteopenia in young adult survivors of childhood cancer. Med Pediatr Oncol 32:272-278

27. Mølgaard C, Thomsen BL, Michaelsen KF 1998 Influence of weight, age an puberty on bone size and bone mineral content in healthy children and adolescents. Acta Paediatr 87:494-499.

28. Slemenda CW, Reister TK, Hui SL, Miller JZ, Christian JC, Johnston CC Jr 1994 Influences on skeletal mineralization in children and adolescents: evidence for varying effects of sexual maturation and physical activity. J Pediatr 125:201-207.

29. Baroncelli GI, Saggese G 2000 Critical ages and stages of puberty in the accumulation of spinal and femoral bone mass: the validity of bone mass measurements. Horm Res 54:2-8

30. Boot AM, van den Heuvel-Eibrink MM, Hählen K, Krenning EP, de Muinck Keizer-Schrama SM 1999 Bone mineral density in children with acute lymphoblastic leukaemia. Eur J Cancer 35:1693-1697

31. Nysom K, Holm K, Hertz H, Muller J, Michaelsen KF, Mølgaard C 2001 Bone mass after treatment for acute lymphoblastic leukaemia in childhood. J Clin Oncol 19:2970-2971

32. Azcona C, Burghard E, Ruza E, Gimeno J, Sierrasesúmaga L 2003 Reduced bone mineralization in adolescent survivors of bone tumors: comparison of quantitative ultrasound and dual-energy x-ray absorptiometry. J Pediatr Hematol Oncol 25:297302 